\title{
Application of liposomes in drug development - focus on gastroenterological targets
}

This article was published in the following Dove Press journal:

International Journal of Nanomedicine

6 April 2013

Number of times this article has been viewed

\author{
Jian-Xin Zhang' \\ Kun Wang' \\ Zheng-Fa Mao' \\ Xin Fan' \\ De-Li Jiang ${ }^{2}$ \\ Min Chen ${ }^{2}$ \\ Lei Cui' \\ Kang Sun' \\ Sheng-Chun Dang' \\ 'Department of General Surgery, \\ the Affiliated Hospital of Jiangsu \\ University, Zhenjiang, Jiangsu Province, \\ People's Republic of China; ${ }^{2}$ School \\ of Chemistry and Chemical \\ Engineering of Jiangsu University, \\ Zhenjiang, Jiangsu Province, \\ People's Republic of China
}

Correspondence: Sheng-Chun Dang; Jian-Xin Zhang

Department of General Surgery, the Affiliated Hospital of Jiangsu University, Zhenjiang 2I 200I, Jiangsu Province, People's Republic of China Tel +8651 I 85082208

Fax +8651188820988

Email dscgu@l63.com;

zhangjx@ujs.edu.cn

\begin{abstract}
Over the past decade, liposomes became a focal point in developing drug delivery systems. New liposomes, with novel lipid molecules or conjugates, and new formulations opened possibilities for safely and efficiently treating many diseases including cancers. New types of liposomes can prolong circulation time or specifically deliver drugs to therapeutic targets. This article concentrates on current developments in liposome based drug delivery systems for treating diseases of the gastrointestinal tract. We will review different types and uses of liposomes in the development of therapeutics for gastrointestinal diseases including inflammatory bowel diseases and colorectal cancer.
\end{abstract}

Keywords: liposome, colorectal cancer, inflammatory bowel disease, drug delivery

\section{Introduction}

Dysregulation of the mucosal immune system is thought to be the cause of inflammatory bowel diseases (IBD), with ulcerative colitis (UC) and Crohn's disease (CD) as the two major forms. IBD has been identified as a major risk factor for colitis associated colorectal cancer (CRC) ${ }^{1-4}$ The immune system consists of innate immunity and adaptive immunity. Innate immunity provides a limited but quick response to infections while adaptive immunity develops a slower but highly specific immune response and provides immunological memories. ${ }^{5}$ Both types of immunity contribute to the pathogenesis of IBD. Defects in innate immunity increase the incidence of $\mathrm{IBD}^{6,7}$ and different $\mathrm{T}$ cell subpopulations are aberrantly activated in $\mathrm{CD}$ and $\mathrm{UC} .{ }^{8}$

Chronic inflammation may trigger dysplasia by inducing genetic and epigenetic changes in intestinal epithelial cells. ${ }^{9-13}$ Once initiated, the fate of dysplastic cells is determined by the balance between the effect of growth factors and cytokines and the subset of immune cells that is activated. ${ }^{14}$ It is thought that the Th1 immune response can prevent tumor progression and induce cell death, while Th2 and Th17 responses promote cell proliferation and tumor progression..$^{14,15}$

Diseases of the gastrointestinal (GI) tract, including IBD and CRC, present challenging targets for drug delivery, particularly by the oral route, as minimal systemic absorption and maximal intestinal wall drug levels are desired. ${ }^{16}$ The GI tract itself presents a harsh environment for medicines, for example, changing $\mathrm{pH}$, various enzymes, the immune response, first pass liver metabolism, intestinal permeability, and interaction with food/mucus. Nonspecific drug absorption and clearance require higher doses which may result in higher toxicity.

Recent advances in nanotechnology research opened up a vast potential for developing efficient drug delivery systems for GI targets. As a type of nanoparticle, 
liposomes have increasingly become an important tool for developing targeted delivery of therapeutics or imaging contrast agents in specific targets to minimize side effects and improve therapeutic effects. ${ }^{16,17}$ Liposomes are artificially prepared lipid bilayer vesicles that encapsulate an aqueous phase in which drugs, nutrients, or imaging enhancing agents can be stored. They are nontoxic, nonhemolytic, and nonimmunogenic. ${ }^{16}$ Conventional liposomes are composed of only natural phospholipids which are absorbed and cleared by the reticuloendothelial system in vivo and have relatively low stability in vitro. Enormous efforts have been dedicated to improve the characteristics and functionality of liposomes. This review will focus on recent advancements in developing liposome based drug delivery systems for GI diseases.

\section{Application of liposomes in treating intestinal inflammatory diseases}

IBD, characterized by chronic inflammation of the gut mucosa, is manifested as either CD or UC. Macrophages and dendritic cells downregulate neutrophil infiltration to confer a protective role during the development of acute colitis. ${ }^{18}$ Data has shown that Th1 related cytokines (eg, tumor necrosis factor, interferon- $\gamma$, and interleukin [IL]-12) as well as Th17 associated cytokines (eg, IL-17A, IL-21, IL-23) are significantly increased in inflamed mucosa of $\mathrm{CD}$, whereas Th2 cytokines such as IL-5 and IL-13 are upregulated in inflamed areas of UC. ${ }^{19-21}$

It is well documented that CD40/CD40L interaction plays a critical role in both the humoral and cellular immune response as well as in the pathogenesis of IBD. ${ }^{22}$ Anti-CD40 and anti-CD40L antibodies are efficient in relieving inflammation, such as in colitis, but severe side effects prevent their use for treatment. ${ }^{23-25}$ A charge reversible liposome encapsulated CD40 antisense oligonucleotide has shown great potency in supressing colitis in animals and significantly reduced $\mathrm{T}$ lymphocyte activation and proinflammatory cytokine secretion. ${ }^{26,27}$ Local administration of cationic liposomes complexed with IL-4 and IL-10 genes was expected to reduce inflammation in patients with severe IBD of the rectum and avoid toxic systemic side effects. ${ }^{28}$ Transferrin (TF) and its receptor (TfR) were shown to be overexpressed in inflamed colonic mucosa. ${ }^{29,30}$ Tirosh et al reported that negatively charged liposomes bound to TF in an acidic environment of inflamed colon mucosa ${ }^{29}$ and anti-TfR antibody conjugated liposomes significantly improve the accumulation of immunoliposome in the mucosa of dinitrobenzensulfonic acid (DNBS) induced rat, ${ }^{30}$ which provides a target and potential drug delivery strategy to treat UC.
Chronically elevated radical oxygen species levels are an important element in inducing inflammation in the intestinal mucosa and in the pathogenesis of IBD. ${ }^{31}$ Cationic liposomes increased residence time and uptake of superoxide dismutase (SOD) and the SOD mimic tempamine by colonic cells in vitro and in ex vivo models. ${ }^{32}$ Anionic liposomes were able to deliver SOD, tempamine, and catalase to inflamed rat intestinal mucosa and achieved longer residence time and better uptake for targeted treatment of UC. ${ }^{33}$ Carnitine loaded liposomes were able to correct butyrate metabolism in colonocytes in a DNBS induced rat colitis model. ${ }^{34}$ These liposomal agents were able to inhibit local oxidative stress and reduce mucosal inflammation.

Helicobacter pylori infection represents a risk factor for adenomatous polyps and adenocarcinoma of the colon caused by chronic inflammation ${ }^{35}$ and $H$. pylori poses an increasing challenge to the clinical management of the infection. ${ }^{36}$ An intravenous injection of clodronate liposomes inhibited expression of macrophage related cytokines, reduced $H$. bilis colonization, and H. bilis induced typhlocolitis by depleting macrophages in a Rag2 $2^{-/}$mouse model. ${ }^{37}$ Clodronate containing liposomes were also effective in protecting against intestinal mucosal injury caused by severe acute pancreatitis in rats. ${ }^{38} \mathrm{~A}$ double liposome based dual drug (amoxicillin and ranitidine bismuth citrate) system showed prolonged sustained drug release, efficient binding to $H$. pylori, enhanced bacterial growth inhibition, antisecretory, and ulcer protective ability in vitro and in vivo..$^{39,40}$

These promising effects of liposomal formulated agents on treating intestinal inflammation or Helicobacter infection were obtained from in vitro or animal models (Table 1). It remains extremely challenging to develop new efficient and safe medications for treating intestinal inflammation even with advances in liposome and other nanoparticle research.

\section{Liposomal development and application for $\mathbf{G I}$ cancers}

$\mathrm{CRC}$ is ranked second for both new cancer cases and cancer related deaths in the United States. ${ }^{41}$ Limiting the systemic toxic side effects of conventional chemotherapeutic agents is a difficult challenge for new CRC (and other cancers) drug development. Proper liposomal formulation was able to increase anticancer efficacy and reduce drug related toxicity in human gastric and CRC bearing mouse models, which opened new avenues for developing more efficient and safer drugs for GI cancers. ${ }^{42-44}$

Within a short period of time since liposomes were first described, liposome production has evolved from simple 
Table I Liposomes developed for gastrointestinal diseases other than cancer

\begin{tabular}{llll}
\hline Liposome type & Payload & Experimental model & Reference \\
\hline Amphoteric & CD40 antisense oligonucleotide & Balb/c TNBS-induced colitis & 26 \\
Anionic & SOD, TMN, catalase & Rat TNBS-induced colitis & 33 \\
Anti-TfR conjugated & None & Rat TNBS-induced colitis & 30 \\
Cationic & IL-4 and IL-I0 gene & Severe IBD patients & 28 \\
Cationic & SOD, TMN & HT-29 cells and rat colon sac & 32 \\
Charge reversible & CD40 antisense oligonucleotide & Rat TNBS-induced colitis & 27 \\
Double liposome & Amox and RBC & H. pylori & 40 \\
Liposome & Carnitine & Rat TNBS-induced colitis & 34 \\
Liposome & Clodronate & Rag2 & 37 \\
Liposome & Clodronate & Rat Sap-induced intestinal mucosal injury & 38 \\
Negatively charged at low $\mathrm{pH}$ & None & Rat TNBS-induced colitis & 29 \\
\hline
\end{tabular}

Abbreviations: $H$, Helicobacter; IBD, inflammatory bowel disease; IL, interleukin; Rag2, recombination activating gene 2; RBC, ranitidine bismuth citrate; SAP, severe acute pancreatitis; SOD, superoxide dismutase; TfR, transferrin receptor; TMN, tempamin; TNBS, 2,4,6-trinitrobenzene sulfonic acid.

naked liposomes (Figure 1A) to stealth (Figure 1C) and/or actively targeted liposomes (Figure 1D, 1E) with variable lipid components, triggering mechanisms (Figure 1B), and conjugating molecules.$^{45}$ The advancement in preparing new types of liposomes has helped research in developing new therapeutics for GI cancers (Table 2). Liposomal curcumin was found to be a potent antitumor agent which effectively inhibited the proliferation of SW-620 human CRC cells. ${ }^{46}$ Liposomal formulation of different anticancer agents was able to sensitize human CRC cells to thermotherapy and thermochemotherapy ${ }^{47}$ or reverse drug resistance in these cells. ${ }^{48}$ Using natural unsaturated and hydrogenated phosphatidylcholines, liposomes with a high content of paclitaxel (PTX) were produced and showed lower acute toxicity and higher efficacy against human cancer in animal models when compared with Taxol. ${ }^{49}$ The combination of a liposomal anticancer drug with other drugs in free or liposomal form has shown very promising synergistic anticancer activity ${ }^{50,51}$ but a combination of liposomal fluoroorotic acid and liposomal irinotecan failed to show, in the $\mathrm{C} 26$ tumor mouse model, the synergistic activity observed in $\mathrm{C} 26$ cells in vitro, ${ }^{51}$ highlighting the challenge of designing multidrug treatments based on in vitro cytotoxicity results. Successful Phase II trials of liposomal drugs in treating advanced CRC or gastric can$\operatorname{cer}^{52,53}$ provide confidence for research into designing new liposomes with different components or new liposomal drug formulations for GI cancer drug development.

\section{Hybrid liposomes}

First developed by Ueoka et al, hybrid liposomes were prepared by simple sonication of a mixture of phospholipids and a surfactant in buffer solutions. ${ }^{54}$ Hybrid liposomes composed of L-a-dimyristoylphosphatidylcholine (DMPC) and polyoxyethylene(n)dodecyl ether $\left(\mathrm{C}_{12}(\mathrm{EO})_{\mathrm{n}}\right)$ were able to inhibit the proliferation of and induce apoptosis in human
CRC cells in vitro. ${ }^{55-57}$ Intravenous administration of DMPC/ $\mathrm{C}_{12}(\mathrm{EO})_{\mathrm{n}}$ or DMPC/docosahexaenoic acid hybrid liposomes into a liver metastases mouse model of xenografted human CRC exhibited significant therapeutic effects. ${ }^{58-60}$ Hybrid liposomes preferentially accumulated into cancer cells and triggered cancer cell apoptosis which resulted in the inhibition of hepatic malignant transformation and prolonged survival of CRC mice with liver metastasis. At the same time, these hybrid liposomes did not show detectable toxicity in vivo. The promising therapeutic benefits shown by hybrid liposomes warrant further pharmacokinetic, pharmacodynamic, and toxicity studies, as well as formulations with other anticancer agents.

\section{PEGylated liposomes}

To combat the rapid removal of liposomes from the blood circulation, mainly into the liver and spleen by phagocytic cells of the mononuclear phagocyte system, intensive research was undertaken to modify the components of liposomes to increase their bioavailability. ${ }^{61}$ Conjugating polyethylene glycol (PEG) to liposomes (ie, PEGylation) reduced phagocytic recognition, improved pharmacokinetics, and increased biological stability. ${ }^{61}$ Pegylation of liposomal PTX drastically increased its in vivo stability, delivered significantly more PTX to tumor tissue, and improved PTX anticancer effects in $\mathrm{C} 26$ tumor bearing mice. ${ }^{62}$ Similarly, PEGylated liposomal formulated mitomycin $\mathrm{C}$ lipid based prodrug had a longer half-life, lower toxicity, and higher anticancer potency than conventional chemotherapy when treating gastric, colon, and pancreatic cancers. ${ }^{43}$ In other cases, PEG or lowdensity lipoprotein (LDL) masked liposomal formulations were able to improve therapeutic effects in CRC and other cancer xenograft models ${ }^{63}$ or reverse drug resistance. ${ }^{64}$

A large amount of effort has been dedicated to explore the formulation and characterization of PEG liposomal oxaliplatin (L-OHP). In the SW480 human CRC cell line, PEGylated 


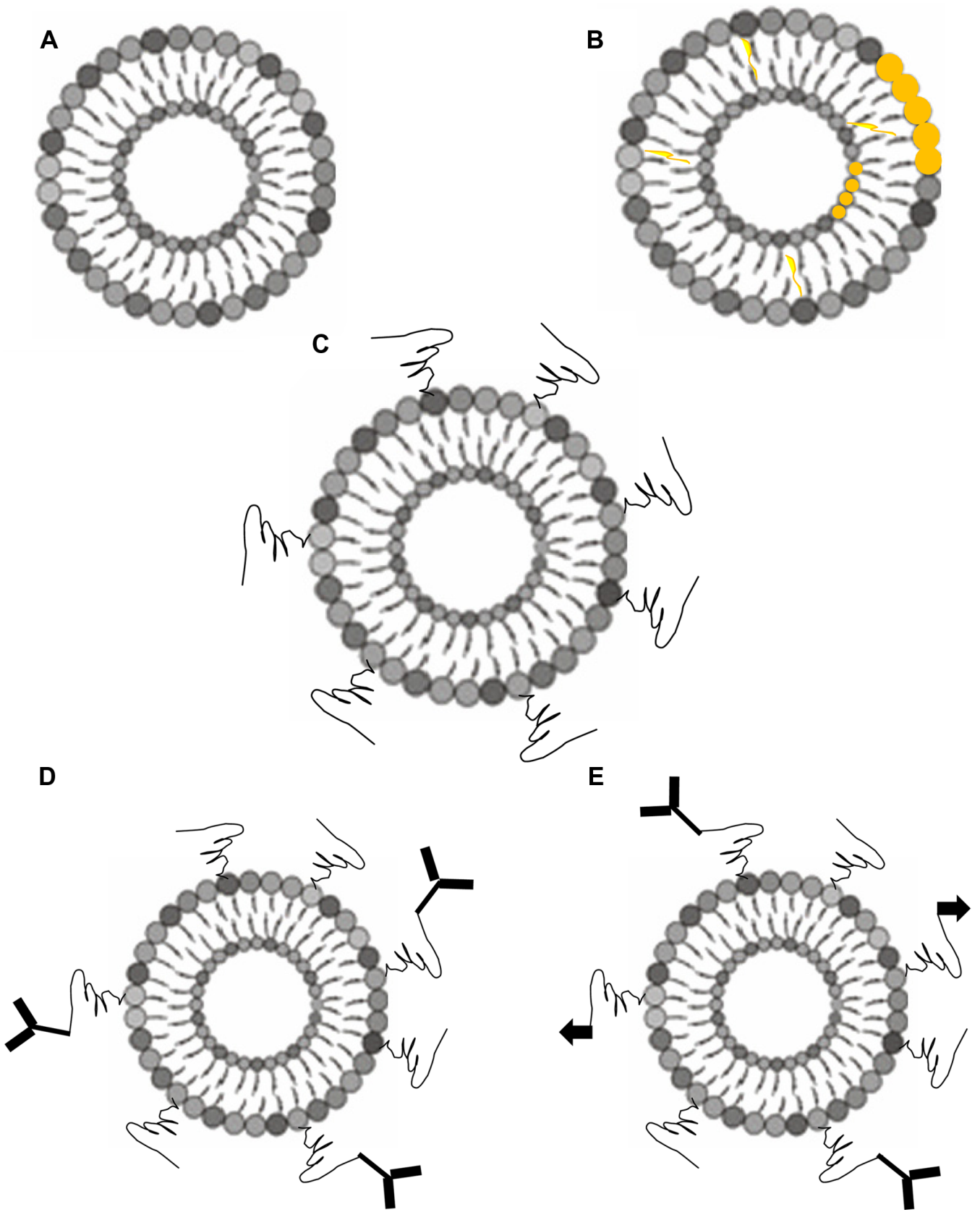

Figure I Schematic illustration of major types of liposomes. (A) Traditional liposomes; (B) liposomes with destabilizing molecules or additional lipid components; (C) stealth liposomes; (D) stealth liposomes conjugated with targeting molecules; and (E) stealth liposomes conjugated with two different targeting molecules.

liposomal L-OHP induced a significantly stronger apoptotic response than the same dose of free L-OHP, ${ }^{65,66}$ indicating enhanced anticancer potency of PEGylated liposomal L-OHP. Apoptosis was mediated by Fas/FasL through the caspase 8 pathway ${ }^{65}$ and by changing the expression of cyclins and influencing cell cycle arrest. ${ }^{66}$ PEG liposomal L-OHP was found to preferably accumulate in tumor tissue after intravenous injection into CRC xenografted nude mice, which promoted antiapoptotic pathways while inhibiting proapoptotic pathways, and resulted in longer survival time ${ }^{67} \mathrm{~A}$ combination of oral metronomic S-1 dosing with intravenous injection of PEG liposomal L-OHP exerted excellent anticancer efficacy without severe overlapping side effects in a murine CRC model. ${ }^{68}$ This combinatory regimen may be an alternative to the current therapeutic regimen for advanced CRC.

\section{Liposomes with triggered drug release}

Although pegylation increased the circulation time of liposomes and tumor tissue drug accumulation, cancer cell 
Table 2 Liposomes developed for gastrointestinal cancers

\begin{tabular}{|c|c|c|c|}
\hline Liposome type & Payload & Experimental model & Reference \\
\hline Anionic & Doxorubicin & HT29 and HT29-dx cells & 48 \\
\hline Anti-VEGFR2-PEG & Doxorubicin & HT29-bearing mice & 114 \\
\hline Cationic & Temoporfin & COLO206 cells and HT29-bearing mice & 85,86 \\
\hline Cationic & Adenovirus-hEndostatin & CT26-bearing mice & 116 \\
\hline Cationic & mEndostatin & HCTII 6 cells and CT26-bearing mice & 117 \\
\hline Cationic & FL or FL/TRAIL gene & Lovo cells & 118,119 \\
\hline Cationic & Cytosine deaminase gene & HR-8348 human rectal cancer cells and bearing mice & 121 \\
\hline DOPC-neurotensin & Doxorubicin & HT29 and TE67I cells & 109 \\
\hline Dual & Vinorelbine/indium-I II oxine & HT29/luc mice & 93 \\
\hline Hybrid & None & WiDr cells & 55 \\
\hline Hybrid & None & HCTII6 cells & 56,57 \\
\hline Hybrid & None & Liver metastasis of human colon carcinoma mouse models & $58-60$ \\
\hline LDL-masked & Doxorubicin & HT29 and HT29-dx cells & 64 \\
\hline Liposome & Betulinic acid & Nude mice xenografted with human colon and lung cancer tumors & 42 \\
\hline Liposome & Curcumin & SW-620 colon cancer cells, A-459 lung cancer cells & 46 \\
\hline Liposome & Quercetin & CT26 colon cancer cells and CT26 mouse model & 47 \\
\hline Liposome & Paclitaxel & $\mathrm{C} 26$ cells and $\mathrm{PCI}$ 4PE6/AS2 bearing mice & 49 \\
\hline Liposome & Fluoroortic acid/irinotecan & C26 cells and $\mathrm{C} 26$ mouse model & 51 \\
\hline Liposome & Aroplatin & Advanced colorectal cancer patients & 52 \\
\hline Liposome & Pyropheophorbide-a methyl ester & HCTII 6 cells & 87 \\
\hline Liposome & 5, I5-diaryl-tetrapyrrole derivative & HCTII 6 cells & 88 \\
\hline Liposome & Par-4 gene & HT29-bearing mice & 122 \\
\hline Magnetic & Docetaxel & MKN45-bearing Balb/c/nu/nu mice & 79 \\
\hline PEGylated & Mitomycin C & $\begin{array}{l}\text { N87 gastric carcinoma }(\mathrm{Ca}), \mathrm{HCT} I 5 \text { colon } \mathrm{Ca} \text {, and Panc-I } \\
\text { pancreatic } \mathrm{Ca} \text { models implanted s.c. in CDI nude mice }\end{array}$ & 43 \\
\hline PEGylated & Honokiol/cisplatin & C26 mouse model & 50 \\
\hline PEGylated & $\begin{array}{l}\text { Doxorubicin, 5-fluorouracil and cisplatin } \\
\text { or mitomycin-C, } 5 \text {-fluorouracil and cisplatin }\end{array}$ & Advanced gastric cancer patients & 53 \\
\hline PEGylated & Paclitaxel & C26 bearing mice & 62 \\
\hline PEGylated & CKD-602 & HT29, A375, ES-2, and H82 tumor xenografted mice & 63 \\
\hline PEGylated & Oxaliplatin & SW480 & 65,66 \\
\hline PEGylated & Oxaliplatin & CRC-xenografted mice & 67,68 \\
\hline PEGylated & Indium-III oxine & HT29/luc mice & 92 \\
\hline PEGylated & Indium- I I I vinorelbine & CT-26/luc mice & 94,95 \\
\hline PEGylated & (III)In-vinorelbine/(I88)Re-doxorubicin & C26-bearing mice & 100 \\
\hline PEGylated & shRNA anti-kitenin & Colon cancer-bearing mice & 120 \\
\hline $\mathrm{pH}$-sensitive & Fe-porphyrin & Gastric cancer cells & 75 \\
\hline $\mathrm{pH}$-sensitive & 5-fluorouracil & HT-29 cells & 76 \\
\hline $\mathrm{pH}$-sensitive-folate & Calcein/cytosine-beta-D-arabinofuranoside & KB human oral cancer cells & 77 \\
\hline pH-sensitive-PR_b & Calcein & CT26.WT cells & 78 \\
\hline Rhenium-I I 8 labeled & 5 -fluorouracil & C26/LS-I74T colon cancer-bearing mice & 96,97 \\
\hline Rhenium- I I 8 labeled & Doxorubicin & C26-bearing mice & 98,99 \\
\hline Sterically stabilized & Cisplatin & C26-bearing mice & 80 \\
\hline Sulfatide-containing & Doxorubicin & HT-29 xenografted mice & 44 \\
\hline TF-PEGylated & None & C26-bearing mice & 103 \\
\hline TF-PEGylated & Cisplatin & MKN45P-bearing mice & 104 \\
\hline TF-PEGylated & Mercaptoundecahydrododecaborate & C26-bearing mice & 105 \\
\hline Thermsensitive & Doxorubicin & C26 tomor-bearing mice & $69,70,72$ \\
\hline Thermsensitive & Lucifer yellow iodoacetamide & CT26 colon cancer cells and CT26 mouse model & 71 \\
\hline Trastuzumab labeled & Docetaxel & $\mathrm{NCl}-\mathrm{N} 87$ gastic cancer-bearing mice & 113 \\
\hline
\end{tabular}

Abbreviations: CRC, colorectal cancer; DOPC, Dioleoylphosphatidylcholine; FL, fms-related tyrosine kinase 3 ligand; LDL, low density lipoprotein; PEG, polyethylene glycol; PR_b, a fibronectin-mimetic peptide; TF, transferrin; TRAIL, tumor necrosis factor (ligand) superfamily, member I0; VEGFR2, Vascular endothelial growth factor receptor 2 .

targeting and drug release were still not controlled by PEG liposomes. Efforts have been made to develop liposomes so that drug release is triggered by changes in physical cues.

Thermosensitive liposomes (TSLs) are a promising tool for controlled drug delivery in combination with local hyperthermia. Long circulating TSLs in combination with local hyperthermia was able to deliver two to six times more encapsulated therapeutic or imaging agents to tumor tissue than either liposome alone or free drug, which resulted in inhibited tumor growth and prolonged survival time. ${ }^{69-71}$ TSLs can 
also be engineered to deliver anticancer drugs to tumor tissue and to carry magnetic resonance imaging agent so that drug release can be monitored by MRI signal intensity after being intravenously injected into $\mathrm{C} 26$ tumor bearing mice. ${ }^{72}$

The search for liposomes with increased ability to mediate intracellular delivery of therapeutics resulted in the development of $\mathrm{pH}$ sensitive liposomes, which have potential application in treating digestive tract diseases such as some tumors or inflamed tissues that are more acidic than normal tissues. ${ }^{73,74}$ Conventional dioleoyl phosphatidylethanolamine (DOPE) based pH sensitive liposomes achieved longer circulation time and tumor targeted delivery by incorporation of PEG. ${ }^{74}$ The new generation of $\mathrm{pH}$ sensitive liposomes that employ $\mathrm{pH}$ sensitive lipids other than DOPE show promise to efficiently deliver anticancer agents to cancer cells. ${ }^{75,76}$ Functionalizing $\mathrm{pH}$ sensitive liposomes with overexpressed cancer cell surface receptors further enhanced their ability to target cancer cells in a specific manner. ${ }^{77,78}$

There were also attempts to explore other types of liposomes for treating GI cancer to enhance tumor specific drug delivery. ${ }^{79,80}$ Injecting docetaxel embedded magnetoliposomes into human MKN45 gastric cancer bearing mice, followed by exposure to an alternating current or magnetic field and local hyperthermia, produced positive results where the amount of drug required for inhibiting cancer growth was greatly reduced, the size of the tumor was decreased, and the survival time was prolonged. ${ }^{79}$ Ultrasound was also utilized to trigger cisplatin release from sterically stabilized liposomes and almost $70 \%$ of liposomal cisplatin was released in tumor tissue, resulting in tumor regression. ${ }^{80}$

\section{Liposomal formulated photosensitizers and radiochemotherapeutics}

Photosensitizers have been used to treat many diseases including brain cancer and lung cancer. ${ }^{81}$ Photodynamic therapy has also been intensively studied for the potential treatment of CRC. ${ }^{82-84}$ Liposomal temoporfin can selectively target tumor cells with rapid biodistribution and clearance from the blood stream. ${ }^{85,86}$ Liposomes encapsulated with novel photosensitizers, such as pyropheophorbide-a methyl ester and 5,15-diaryl-tetrapyrrole derivatives, had significantly higher intracellular drug delivery ${ }^{87}$ or more potent cytotoxicity than temoporfin $^{88}$ in the HCT-116 CRC cell line. Even with the potential benefits of photodynamic therapy, much work needs to be done before clinical application of liposomal formulation of photosensitizers for CRC treatment is accepted as all work so far has been performed in cell lines.
Molecular imaging is the most common use for nuclear medicine in cancer management ${ }^{89,90}$ with a report of cases of radiotherapy. ${ }^{91}$ Recently, there has been much effort to progress the investigation of liposome formulation of radiochemotherapeutic and radioimaging agents. Chow et al found that indium-111 ((111)In) labeled oxine delivered by liposomes with a higher concentration of PEG (6 mol\%) had a longer circulation time due to reduced phagocytic clearance and enhanced tumor targeting efficiency which resulted in a better therapeutic outcome. ${ }^{92}$ Dual liposomes encapsulating vinorelbine and (111)In oxine or PEGylated liposomes encapturing (111)In and vinorelbine had the combined benefits of chemotherapy and radiotherapy. ${ }^{93-95}$ Rhenium-188 ((188)Re) labeled PEGylated liposomes carrying anticancer drugs showed the potential benefits of tumor specific drug accumulation and cancer growth inhibition. ${ }^{96-99}$ PEGylated liposomes encapsulating (111)Re and vinorelbine was as effective as PEG liposomal (188)Re and doxorubicin for radiochemotherapy of $\mathrm{CRC}$ models. ${ }^{100}$

\section{Active targeting liposomes}

Passive targeting liposomes were improved to escape reticuloendothelial clearance and increase accumulation in tumor tissues. However, their circulation time and amount of drug targeted to tumors are impacted by every pathophysiological condition of the body. Active targeting liposomes deliver loaded drugs to target cells based on the attachment of specific ligands to the surface of liposomes to recognize and bind to surface markers of pathological cells. ${ }^{101} \mathrm{TfR}$ is overexpressed in many cancer types so it is an attractive molecule for targeted cancer therapy. ${ }^{102} \mathrm{TF}$ conjugated PEGylated liposomes possess the advantage of both systems - long circulation capability of pegylation and TfR specific targeting of cancer cells. ${ }^{103-105}$ TF PEG liposomes can deliver chemotherapeutic ${ }^{104}$ and radiotherapeutic agents $^{105}$ specifically into TfR overexpressing cancer cells via receptor mediated endocytosis of liposomes, achieving increased intracellular drug amount, stronger tumor inhibition, and prolonged survival.

The integrin family of cell adhesion proteins play key roles in promoting cell proliferation, tumor angiogenesis, and metastasis. ${ }^{106}$ Accordingly, antagonists of several integrins have been investigated as potential therapeutics for cancer and other diseases. After conjugating high affinity integrin $\alpha 5 \beta 1$ and specific binding fibronectin mimetic peptide PR_b, pH sensitive PEG liposomes specifically bind and rapidly release loaded agents into integrin $\alpha 5 \beta 1$ expressing cancer cells. ${ }^{78}$ 
Neurotensin and neurotensin receptor 1 have been identified as factors promoting tumor growth and cancer metastasis. ${ }^{107}$ The selective neurotensin receptor 1 (NTR-1) antagonist sensitized prostate cancer cells to radiation therapy. ${ }^{108}$ Functionalization with neurotensin peptides significantly improved the ability of liposomes to deliver chemotherapeutics into CRC cells and resulted in a four fold increase in cytotoxicity. ${ }^{109} \mathrm{Her} 2$ and VEGFR are overexpressed in many cancer types including gastric cancer ${ }^{110}$ and CRC. ${ }^{111}$ Anti-Her2 and anti-VEGFR immunoliposomes provide a novel tool for safe and efficient immnochemotherapy of Her2 or VEGFR positive GI cancers. ${ }^{112-114}$

\section{Application of liposomes to gene therapy}

Advances in molecular and cellular biology in gene transfer including liposomal formulation of genetic material have made it likely that gene therapy will play an increasingly important role in cancer treatment. ${ }^{115}$ Liposome mediated gene therapy can be an independent treatment ${ }^{116-120}$ or be used in combination with other treatments. ${ }^{121,122}$ Liposome encapsulated endostatin gene suppressed tumor growth and prolonged survival time of human CRC carrying mice and displayed comparable tumor suppressive effects to bevacizumab. ${ }^{16,117}$ To avoid the unpredictable side effects of viral vectors, plasmids were evaluated in the liposomal formulation. ${ }^{118,119,121,122}$ Liposomal fms-related tyrosine kinase 3 ligand (pEGF-FL) induced cell death in Lovo cells ${ }^{118}$ and a combination of FL and tumor necrosis factor (ligand) superfamily, member 10 (TRAIL) genes in cationic liposomes achieved superior anticancer effects than single gene therapy. ${ }^{119}$ While overexpressing cancer inhibitors can suppress tumor progression, knockdown of oncogenes with liposomal shRNA would have the same effect. PEG liposome encapsulated shRNA against the kitenin gene inhibited CRC growth in mice and enhanced apoptotic signals. ${ }^{120}$ Combined with radiation, liposomal cytosine deaminase gene and 5-fluorocytosine reduced tumor volune more than $80 \%$ when compared to control in mice bearing human rectal cancer. ${ }^{121}$ Par-4 plasmid delivered by liposomes enhanced 5-fluorouracil induced cancer cell apoptosis, ${ }^{122}$ indicating liposome mediated gene therapy combined with chemotherapeutics or radiation can be a safe and efficient treatment for CRC.

\section{Future perspective}

In the past decade, advances have been made in generating new types of liposomes and in developing strategies to utilize liposomes in treating GI diseases. Increasing drug accumulation at the target tissue and minimizing systematic side effects are still the biggest challenges in designing new drug delivery systems. As PEGylated liposomes inherit the advantage of prolonged circulating time over conventional liposomes, maximizing the capacity of PEGylated liposomes would be of great interest in future development of drug delivery systems. A combination strategy may be conceived by formulating therapeutics in PEGylated liposomes functionalized with active targeting molecules (such as antibodies, growth factors, peptides, carbohydrates, lipoproteins, etc) for targeted tissue accumulation of drugs and incorporating components sensitive to $\mathrm{pH}$, temperature, light, ultrasound, or magnetism for controlled drug release. Success in developing such combination of liposomes would provide safe and efficient drug delivery for GI diseases ranging from IBD to cancers.

\section{Acknowledgments}

We apologize to the authors whose works were not cited in this review due to the large number of relevant publications. This work was supported by National Natural Science Foundation of China (No 81070287), the Natural Science Foundation of Jiangsu Province (No BK2011484, BK2012704), and the Zhenjiang Science and Technology Committee (No SH2011026).

\section{Disclosure}

The authors report no conflicts of interest in this work.

\section{References}

1. Eaden JA, Abrams KR, Mayberry JF. The risk of colorectal cancer in ulcerative colitis: a meta-analysis. Gut. 2001;48(4):526-535.

2. Bernstein CN, Blanchard JF, Kliewer E, Wajda A. Cancer risk in patients with inflammatory bowel disease: a population-based study. Cancer. 2001;91(4):854-862.

3. Ekbom A, Helmick C, Zack M, Adami HO. Ulcerative colitis and colorectal cancer. A population-based study. N Engl J Med. 1990;323(18): 1228-1233.

4. Canavan C, Abrams KR, Mayberry J. Meta-analysis: colorectal and small bowel cancer risk in patients with Crohn's disease. Aliment Pharmacol Ther. 2006;23(8):1097-1104.

5. Siegmund B, Zeitz M. Innate and adaptive immunity in inflammatory bowel disease. World J Gastroenterol. 2011;17(27):3178-3183.

6. Huang JS, Noack D, Rae J, et al. Chronic granulomatous disease caused by a deficiency in p47(phox) mimicking Crohn's disease. Clin Gastroenterol Hepatol. 2004;2(8):690-695.

7. Schinella RA, Greco MA, Cobert BL, Denmark LW, Cox RP. Hermansky-Pudlak syndrome with granulomatous colitis. Ann Intern Med. 1980;92(1):20-23.

8. Fuss IJ, Neurath M, Boirivant M, et al. Disparate CD4+ lamina propria (LP) lymphokine secretion profiles in inflammatory bowel disease. Crohn's disease LP cells manifest increased secretion of IFN-gamma, whereas ulcerative colitis LP cells manifest increased secretion of IL-5. J Immunol. 1996;157(3):1261-1270. 
9. Meira LB, Bugni JM, Green SL, et al. DNA damage induced by chronic inflammation contributes to colon carcinogenesis in mice. J Clin Invest. 2008;118(7):2516-2525.

10. Westbrook AM, Wei B, Braun J, Schiestl RH. Intestinal mucosal inflammation leads to systemic genotoxicity in mice. Cancer Res. 2009; 69(11):4827-4834.

11. Colotta F, Allavena P, Sica A, Garlanda C, Mantovani A. Cancerrelated inflammation, the seventh hallmark of cancer: links to genetic instability. Carcinogenesis. 2009;30(7):1073-1081.

12. Grady WM, Carethers JM. Genomic and epigenetic instability in colorectal cancer pathogenesis. Gastroenterology. 2008;135(4): 1079-1099.

13. Rustgi AK. The genetics of hereditary colon cancer. Genes Dev. 2007;21(20):2525-2538.

14. Rizzo A, Pallone F, Monteleone G, Fantini MC. Intestinal inflammation and colorectal cancer: a double-edged sword? World J Gastroenterol. 2011;17(26):3092-3100.

15. Compare D, Nardone G. Contribution of gut microbiota to colonic and extracolonic cancer development. Dig Dis. 2011;29(6):554-561.

16. Mufamadi MS, Pillay V, Choonara YE, et al. A review on composite liposomal technologies for specialized drug delivery. $J$ Drug Deliv. 2011;2011:939851.

17. Kesisoglou F, Zimmermann EM. Novel drug delivery strategies for the treatment of inflammatory bowel disease. Expert Opin Drug Deliv. 2005;2(3):451-463.

18. Qualls JE, Kaplan AM, van Rooijen N, Cohen DA. Suppression of experimental colitis by intestinal mononuclear phagocytes. J Leukoc Biol. 2006;80(4):802-815.

19. Sartor RB. Mechanisms of disease: pathogenesis of Crohn's disease and ulcerative colitis. Nat Clin Pract Gastroenterol Hepatol. 2006;3(7): 390-407.

20. Shih DQ, Targan SR. Immunopathogenesis of inflammatory bowel disease. World J Gastroenterol. 2008;14(3):390-400.

21. Yadav PK, Liu Z. Current strategies for the treatment of ulcerative colitis. Recent Pat Inflamm Allergy Drug Discov. 2009;3(1): 65-72.

22. Polese L, Angriman I, Scarpa M, et al. Role of CD40 and B7 costimulators in inflammatory bowel diseases. Acta Biomed. 2003; 74 Suppl 2:65-70.

23. Kawai T, Andrews D, Colvin RB, Sachs DH, Cosimi AB. Thromboembolic complications after treatment with monoclonal antibody against CD40 ligand. Nat Med. 2000;6(2):114.

24. Yamada A, Sayegh MH. The CD154-CD40 costimulatory pathway in transplantation. Transplantation. 2002;73(Suppl 1):S36-S39.

25. Sakata K, Sakata A, Kong L, Vela-Roch N, Talal N, Dang H. Monocyte rescue of human T cells from apoptosis is CD40/CD154 dependent. Scand J Immunol. 1999;50(5):479-484.

26. Arranz A, Reinsch C, Papadakis KA, et al. Treatment of experimental murine colitis with CD40 antisense oligonucleotides delivered in amphoteric liposomes. J Control Release. 2012;165(3):163-172.

27. Gao D, Wagner AH, Fankhaenel S, et al. CD40 antisense oligonucleotide inhibition of trinitrobenzene sulphonic acid induced rat colitis. Gut. 2005;54(1):70-77.

28. Rogy MA, Beinhauer BG, Reinisch W, Huang L, Pokieser P. Transfer of interleukin-4 and interleukin-10 in patients with severe inflammatory bowel disease of the rectum. Hum Gene Ther. 2000;11(12): 1731-1741.

29. Tirosh B, Khatib N, Barenholz Y, Nissan A, Rubinstein A. Transferrin as a luminal target for negatively charged liposomes in the inflamed colonic mucosa. Mol Pharm. 2009;6(4):1083-1091.

30. Harel E, Rubinstein A, Nissan A, et al. Enhanced transferrin receptor expression by proinflammatory cytokines in enterocytes as a means for local delivery of drugs to inflamed gut mucosa. PLoS One. 2011;6(9): e24202.

31. Rozga J. The role of reactive oxygen metabolites in the pathogenesis of ulcerative colitis: a speculative synthesis. Mater Med Pol. 1989;21(4): 263-268.
32. Jubeh TT, Antler S, Haupt S, Barenholz Y, Rubinstein A. Local prevention of oxidative stress in the intestinal epithelium of the rat by adhesive liposomes of superoxide dismutase and tempamine. Mol Pharm. 2005;2(1):2-11

33. Jubeh TT, Nadler-Milbauer M, Barenholz Y, Rubinstein A. Local treatment of experimental colitis in the rat by negatively charged liposomes of catalase, TMN and SOD. J Drug Target. 2006;14(3):155-163.

34. D’Argenio G, Calvani M, Casamassimi A, et al. Experimental colitis: decreased Octn2 and Atb0+ expression in rat colonocytes induces carnitine depletion that is reversible by carnitine-loaded liposomes. FASEB J. 2006;20(14):2544-2546.

35. Sonnenberg A, Genta RM. Helicobacter pylori is a Risk Factor for Colonic Neoplasms. Am J Gastroenterol. 2013;108(2):208-215.

36. Chey WD, Wong BC. American College of Gastroenterology guideline on the management of Helicobacter pylori infection. Am J Gastroenterol. 2007;102(8):1808-1825.

37. Muthupalani S, Ge Z, Feng Y, et al. Systemic Macrophage Depletion Inhibits Helicobacter bilis-Induced Proinflammatory CytokineMediated Typhlocolitis and Impairs Bacterial Colonization Dynamics in a BALB/c Rag2-/- Mouse Model of Inflammatory Bowel Disease. Infect Immun. 2012;80(12):4388-4397.

38. Zhang JX, Dang SC, Yin K, Jiang DL. Protective effect of clodronatecontaining liposomes on intestinal mucosal injury in rats with severe acute pancreatitis. Hepatobiliary Pancreat Dis Int. 2011;10(5): 544-551.

39. Singh DY, Prasad NK. Double liposomes mediated dual drug targeting for treatment of Helicobacter pylori infections. Pharmazie. 2011; 66(5):368-373.

40. Jain AK, Agarwal A, Agrawal H, Agrawal GP. Double-liposome-based dual-drug delivery system as vectors for effective management of peptic ulcer. J Liposome Res. 2012;22(3):205-214.

41. Jemal A, Siegel R, Xu J, Ward E. Cancer statistics, 2010. CA Cancer J Clin. 2010;60(5):277-300.

42. Mullauer FB, van Bloois L, Daalhuisen JB, et al. Betulinic acid delivered in liposomes reduces growth of human lung and colon cancers in mice without causing systemic toxicity. Anticancer Drugs. 2011;22(3): 223-233.

43. Gabizon A, Amitay Y, Tzemach D, Gorin J, Shmeeda H, Zalipsky S. Therapeutic efficacy of a lipid-based prodrug of mitomycin $\mathrm{C}$ in pegylated liposomes: studies with human gastro-entero-pancreatic ectopic tumor models. J Control Release. 2012;160(2):245-253.

44. Lin J, Yu Y, Shigdar S, et al. Enhanced antitumor efficacy and reduced systemic toxicity of sulfatide-containing nanoliposomal Doxorubicin in a xenograft model of colorectal cancer. PLoS One. 2012;7(11): e49277.

45. Cattel L, Ceruti M, Dosio F. From conventional to stealth liposomes: a new frontier in cancer chemotherapy. Tumori. 2003;89(3):237-249.

46. Rahman S, Cao S, Steadman KJ, Wei M, Parekh HS. Native and betacyclodextrin-enclosed curcumin: entrapment within liposomes and their in vitro cytotoxicity in lung and colon cancer. Drug Deliv. 2012;19(7): 346-353.

47. He B, Wang X, Shi HS, et al. Quercetin Liposome Sensitizes Colon Carcinoma to Thermotherapy and Thermochemotherapy in Mice Models. Integr Cancer Ther. 2012.

48. Riganti C, Voena C, Kopecka J, et al. Liposome-encapsulated doxorubicin reverses drug resistance by inhibiting P-glycoprotein in human cancer cells. Mol Pharm. 2011;8(3):683-700.

49. Kan P, Tsao CW, Wang AJ, Su WC, Liang HF. A liposomal formulation able to incorporate a high content of Paclitaxel and exert promising anticancer effect. J Drug Deliv. 2011;2011:629234.

50. Cheng N, Xia T, Han Y, He QJ, Zhao R, Ma JR. Synergistic antitumor effects of liposomal honokiol combined with cisplatin in colon cancer models. Oncol Lett. 2011;2(5):957-962.

51. Riviere K, Kieler-Ferguson HM, Jerger K, Szoka FC Jr. Anti-tumor activity of liposome encapsulated fluoroorotic acid as a single agent and in combination with liposome irinotecan. J Control Release. 2011; 153(3):288-296. 
52. Dragovich T, Mendelson D, Kurtin S, Richardson K, Von Hoff D, Hoos A. A Phase 2 trial of the liposomal DACH platinum L-NDDP in patients with therapy-refractory advanced colorectal cancer. Cancer Chemother Pharmacol. 2006;58(6):759-764.

53. Cascinu S, Galizia E, Labianca R, et al. Pegylated liposomal doxorubicin, 5-fluorouracil and cisplatin versus mitomycin-C, 5-fluorouracil and cisplatin for advanced gastric cancer: a randomized phase II trial. Cancer Chemother Pharmacol. 2011;68(1):37-43.

54. Ueoka R, Moss R, Swarup S. Extraordinary micellar enantioselectivity coupled to altered aggregate structure. J Am Chem Soc. 1985; 107(7):2185-2186

55. Komizu Y, Matsumoto Y, Ueoka R. Membrane targeted chemotherapy with hybrid liposomes for colon tumor cells leading to apoptosis. Bioorg Med Chem Lett. 2006;16(23):6131-6134.

56. Hino M, Ichihara H, Matsumoto Y, Ueoka R. Anti-tumor Effects of Cationic Hybrid Liposomes against Colon Carcinoma along with Apoptosis in Vitro. Biol Pharm Bull. 2012;35(11):2097-2101.

57. Komizu Y, Ueoka H, Goto K, Ueoka R. Remarkable inhibitory effects of hybrid liposomes on growth of human colon cancer cells through induction of cell cycle arrest along with apoptosis. Int J Nanomedicine. 2011;6:1913-1920.

58. Ichihara H, Hino M, Umebayashi M, Matsumoto $Y$, Ueoka R. Intravenous injection of hybrid liposomes suppresses the liver metastases in xenograft mouse models of colorectal cancer in vivo. Eur J Med Chem. 2012;57:143-148.

59. Ichihara H, Funamoto K, Matsushita T, Matsumoto Y, Ueoka R. Histological bioanalysis for therapeutic effects of hybrid liposomes on the hepatic metastasis of colon carcinoma in vivo. Int $J$ Pharm. 2010;394(1-2):174-178.

60. Ichihara H, Zako K, Komizu Y, Goto K, Ueoka R. Therapeutic effects of hybrid liposomes composed of phosphatidylcholine and docosahexaenoic acid on the hepatic metastasis of colon carcinoma along with apoptosis in vivo. Biol Pharm Bull. 2011;34(6):901-905.

61. Rangger C, Helbok A, von Guggenberg E, et al. Influence of PEGylation and RGD loading on the targeting properties of radiolabeled liposomal nanoparticles. Int J Nanomedicine. 2012;7:5889-5900.

62. Yoshizawa Y, Kono Y, Ogawara K, Kimura T, Higaki K. PEG liposomalization of paclitaxel improved its in vivo disposition and anti-tumor efficacy. Int J Pharm. 2011;412(1-2):132-141.

63. Yu NY, Conway C, Pena RL, Chen JY. STEALTH liposomal CKD-602, a topoisomerase I inhibitor, improves the therapeutic index in human tumor xenograft models. Anticancer Res. 2007;27(4B):2541-2545.

64. Kopecka J, Campia I, Olivero P, et al. A LDL-masked liposomaldoxorubicin reverses drug resistance in human cancer cells. $J$ Control Release. 2011;149(2):196-205.

65. Yang C, Liu HZ, Fu ZX. PEG-liposomal oxaliplatin induces apoptosis in human colorectal cancer cells via Fas/FasL and caspase-8. Cell Biol Int. 2012;36(3):289-296.

66. Yang C, Liu HZ, Fu ZX. Effects of PEG-liposomal oxaliplatin on apoptosis, and expression of Cyclin A and Cyclin D1 in colorectal cancer cells. Oncol Rep. 2012;28(3):1006-1012.

67. Yang C, Liu HZ, Lu WD, Fu ZX. PEG-liposomal oxaliplatin potentialization of antitumor efficiency in a nude mouse tumor-xenograft model of colorectal carcinoma. Oncol Rep. 2011;25(6):1621-1628.

68. Doi Y, Okada T, Matsumoto H, Ichihara M, Ishida T, Kiwada H. Combination therapy of metronomic S-1 dosing with oxaliplatincontaining polyethylene glycol-coated liposome improves antitumor activity in a murine colorectal tumor model. Cancer Sci. 2010;101(11) 2470-2475.

69. Maruyama K, Unezaki S, Takahashi N, Iwatsuru M. Enhanced delivery of doxorubicin to tumor by long-circulating thermosensitive liposomes and local hyperthermia. Biochim Biophys Acta. 1993;1149(2): 209-216.

70. Unezaki S, Maruyama K, Takahashi N, et al. Enhanced delivery and antitumor activity of doxorubicin using long-circulating thermosensitive liposomes containing amphipathic polyethylene glycol in combination with local hyperthermia. Pharm Res. 1994;11(8):1180-1185.
71. Wells J, Sen A, Hui SW. Localized delivery to CT-26 tumors in mice using thermosensitive liposomes. Int J Pharm. 2003;261(1-2):105-114.

72. Kono K, Nakashima S, Kokuryo D, et al. Multi-functional liposomes having temperature-triggered release and magnetic resonance imaging for tumor-specific chemotherapy. Biomaterials. 2011;32(5):1387-1395.

73. Karanth H, Murthy RS. pH-sensitive liposomes - principle and application in cancer therapy. J Pharm Pharmacol. 2007;59(4):469-483.

74. Hong MS, Lim SJ, Oh YK, Kim CK. pH-sensitive, serum-stable and long-circulating liposomes as a new drug delivery system. $J$ Pharm Pharmacol. 2002;54(1):51-58.

75. Hiraka K, Kanehisa M, Tamai M, et al. Preparation of $\mathrm{pH}$-sensitive liposomes retaining SOD mimic and their anticancer effect. Colloids Surf B Biointerfaces. 2008;67(1):54-58.

76. Banerjee S, Sen K, Pal TK, Guha SK. Poly(styrene-co-maleic acid)-based $\mathrm{pH}$-sensitive liposomes mediate cytosolic delivery of drugs for enhanced cancer chemotherapy. Int J Pharm. 2012;436(1-2):786-797.

77. Shi G, Guo W, Stephenson SM, Lee RJ. Efficient intracellular drug and gene delivery using folate receptor-targeted $\mathrm{pH}$-sensitive liposomes composed of cationic/anionic lipid combinations. J Control Release. 2002;80(1-3):309-319.

78. Garg A, Kokkoli E. pH-Sensitive PEGylated liposomes functionalized with a fibronectin-mimetic peptide show enhanced intracellular delivery to colon cancer cell. Curr Pharm Biotechnol. 2011;12(8): 1135-1143.

79. Yoshida M, Watanabe Y, Sato M, et al. Feasibility of chemohyperthermia with docetaxel-embedded magnetoliposomes as minimally invasive local treatment for cancer. Int J Cancer. 2010;126(8):1955-1965.

80. Schroeder A, Honen R, Turjeman K, Gabizon A, Kost J, Barenholz Y. Ultrasound triggered release of cisplatin from liposomes in murine tumors. J Control Release. 2009;137(1):63-68.

81. Fayter D, Corbett M, Heirs M, Fox D, Eastwood A. A systematic review of photodynamic therapy in the treatment of pre-cancerous skin conditions, Barrett's oesophagus and cancers of the biliary tract, brain, head and neck, lung, oesophagus and skin. Health Technol Assess. 2010;14(37):1-288.

82. Semelakova M, Mikes J, Jendzelovsky R, Fedorocko P. The proapoptotic and anti-invasive effects of hypericin-mediated photodynamic therapy are enhanced by hyperforin or aristoforin in HT-29 colon adenocarcinoma cells. J Photochem Photobiol B. 2012;117: 115-125.

83. He Y, Ge H, Li S. Haematoporphyrin based photodynamic therapy combined with hyperthermia provided effective therapeutic vaccine effect against colon cancer growth in mice. Int J Med Sci. 2012;9(8): $627-633$.

84. Johnson RP, Chung CW, Jeong YI, Kang DH, Suh H, Kim I. Poly(L-histidine)-tagged 5-aminolevulinic acid prodrugs: new photosensitizing precursors of protoporphyrin IX for photodynamic colon cancer therapy. Int J Nanomedicine. 2012;7:2497-2512.

85. Bombelli C, Caracciolo G, Di Profio P, et al. Inclusion of a photosensitizer in liposomes formed by DMPC/gemini surfactant: correlation between physicochemical and biological features of the complexes. J Med Chem. 2005;48(15):4882-4891.

86. Svensson J, Johansson A, Grafe S, et al. Tumor selectivity at short times following systemic administration of a liposomal temoporfin formulation in a murine tumor model. Photochem Photobiol. 2007;83(5): 1211-1219.

87. Guelluy PH, Fontaine-Aupart MP, Grammenos A, Lecart S, Piette J, Hoebeke M. Optimizing photodynamic therapy by liposomal formulation of the photosensitizer pyropheophorbide-a methyl ester: in vitro and ex vivo comparative biophysical investigations in a colon carcinoma cell line. Photochem Photobiol Sci. 2010;9(9):1252-1260.

88. Gariboldi MB, Ravizza R, Baranyai P, et al. Photodynamic effects of novel 5,15-diaryl-tetrapyrrole derivatives on human colon carcinoma cells. Bioorg Med Chem. 2009;17(5):2009-2016.

89. $\mathrm{Wu} \mathrm{C}, \mathrm{Ma} \mathrm{G}, \mathrm{Li} \mathrm{J}$, et al. In vivo cell tracking via (18)F-fluorodeoxyglucose labeling: a review of the preclinical and clinical applications in cellbased diagnosis and therapy. Clin Imaging. 2013;37(1):28-36. 
90. Kim SH, Won KS, Hwang I, Choi BW, Jo I, Zeon SK. Simultaneous Splenic and Colonic Metastases From Gastric Cancer: Different FDG Avidities According to the Density of Cancer Cells Imaged on FDG

91. Yasuda S, Kamata H, Machida T, et al. A case of isolated paraaortic lymph node recurrence from colon cancer successfully treated with chemoradiotherapy. Tokai J Exp Clin Med. 2012;37(2):47-50.

92. Chow TH, Lin YY, Hwang JJ, et al. Improvement of biodistribution and therapeutic index via increase of polyethylene glycol on drug-carrying liposomes in an HT-29/luc xenografted mouse model. Anticancer Res. 2009;29(6):2111-2120.

93. Chow TH, Lin YY, Hwang JJ, et al. Diagnostic and therapeutic evaluation of $111 \mathrm{In}$-vinorelbine-liposomes in a human colorectal carcinoma HT-29/luc-bearing animal model. Nucl Med Biol. 2008;35(5):623-634.

94. Chow TH, Lin YY, Hwang JJ, et al. Therapeutic efficacy evaluation of 111In-labeled PEGylated liposomal vinorelbine in murine colon carcinoma with multimodalities of molecular imaging. $J$ Nucl Med. 2009;50(12):2073-2081.

95. Lin YY, Li JJ, Chang CH, et al. Evaluation of pharmacokinetics of 111In-labeled VNB-PEGylated liposomes after intraperitoneal and intravenous administration in a tumor/ascites mouse model. Cancer Biother Radiopharm. 2009;24(4):453-460.

96. Tsai CC, Chang $\mathrm{CH}, \mathrm{Chen} \mathrm{LC,} \mathrm{et} \mathrm{al.} \mathrm{Biodistribution} \mathrm{and} \mathrm{pharmacoki-}$ netics of $188 \mathrm{Re}$-liposomes and their comparative therapeutic efficacy with 5-fluorouracil in $\mathrm{C} 26$ colonic peritoneal carcinomatosis mice. Int J Nanomedicine. 2011;6:2607-2619.

97. Hsu CW, Chang YJ, Chang CH, et al. Comparative therapeutic efficacy of rhenium-188 radiolabeled-liposome and 5-fluorouracil in LS-174T human colon carcinoma solid tumor xenografts. Cancer Biother Radiopharm. 2012;27(8):481-489.

98. Chang YJ, Chang CH, Yu CY, et al. Therapeutic efficacy and microSPECT/CT imaging of 188Re-DXR-liposome in a C26 murine colon carcinoma solid tumor model. Nucl Med Biol. 2010;37(1):95-104.

99. Chen LC, Chang CH, Yu CY, et al. Pharmacokinetics, micro-SPECT/CT imaging and therapeutic efficacy of (188)Re-DXR-liposome in C26 colon carcinoma ascites mice model. Nucl Med Biol. 2008;35(8):883-893.

100. Lin YY, Chang CH, Li JJ, et al. Pharmacokinetics and dosimetry of (111)In/(188)Re-labeled PEGylated liposomal drugs in two colon carcinoma-bearing mouse models. Cancer Biother Radiopharm. 2011; 26(3):373-380.

101. Torchilin VP. Passive and active drug targeting: drug delivery to tumors as an example. Handb Exp Pharmacol. 2010;197:3-53.

102. Daniels TR, Bernabeu E, Rodriguez JA, et al. The transferrin receptor and the targeted delivery of therapeutic agents against cancer. Biochim Biophys Acta. 2012;1820(3):291-317.

103. Ishida $\mathrm{O}$, Maruyama $\mathrm{K}$, Tanahashi $\mathrm{H}$, et al. Liposomes bearing polyethyleneglycol-coupled transferrin with intracellular targeting property to the solid tumors in vivo. Pharm Res. 2001;18(7):1042-1048.

104. Iinuma $\mathrm{H}$, Maruyama $\mathrm{K}$, Okinaga $\mathrm{K}$, et al. Intracellular targeting therapy of cisplatin-encapsulated transferrin-polyethylene glycol liposome on peritoneal dissemination of gastric cancer. Int $J$ Cancer. 2002;99(1):130-137.

105. Maruyama K, Ishida O, Kasaoka S, et al. Intracellular targeting of sodium mercaptoundecahydrododecaborate (BSH) to solid tumors by transferrin-PEG liposomes, for boron neutron-capture therapy (BNCT). J Control Release. 2004;98(2):195-207. PET/CT. Clin Nucl Med. 2013;38(1):60-62.

106. Jin $\mathrm{H}$, Varner J. Integrins: roles in cancer development and as treatment targets. Br J Cancer. 2004;90(3):561-565.

107. Dupouy S, Mourra N, Doan VK, Gompel A, Alifano M, Forgez P. The potential use of the neurotensin high affinity receptor 1 as a biomarker for cancer progression and as a component of personalized medicine in selective cancers. Biochimie. 2011;93(9):1369-1378.

108. Valerie NC, Casarez EV, Dasilva JO, et al. Inhibition of neurotensin receptor 1 selectively sensitizes prostate cancer to ionizing radiation. Cancer Res. 2011;71(21):6817-6826.

109. Falciani C, Accardo A, Brunetti J, et al. Target-selective drug delivery through liposomes labeled with oligobranched neurotensin peptides. Chem Med Chem. 2011;6(4):678-685.

110. Ruschoff J, Hanna W, Bilous M, et al. HER2 testing in gastric cancer: a practical approach. Mod Pathol. 2012;25(5):637-650.

111. Ochs AM, Wong L, Kakani V, et al. Expression of vascular endothelial growth factor and HER2/neu in stage II colon cancer and correlation with survival. Clin Colorectal Cancer. 2004;4(4):262-267.

112. Park JW, Kirpotin DB, Hong K, et al. Tumor targeting using anti-her2 immunoliposomes. J Control Release. 2001;74(1-3):95-113.

113. Yamamoto Y, Yoshida M, Sato M, et al. Feasibility of tailored, selective and effective anticancer chemotherapy by direct injection of docetaxel-loaded immunoliposomes into Her2/neu positive gastric tumor xenografts. Int J Oncol. 2011;38(1):33-39.

114. Wicki A, Rochlitz C, Orleth A, et al. Targeting tumor-associated endothelial cells: anti-VEGFR2 immunoliposomes mediate tumor vessel disruption and inhibit tumor growth. Clin Cancer Res. 2012;18(2): 454-464.

115. Ortiz R, Melguizo C, Prados J, et al. New gene therapy strategies for cancer treatment: a review of recent patents. Recent Pat Anticancer Drug Discov. 2012;7(3):297-312.

116. Wang L, Yao B, Li Q, et al. Gene therapy with recombinant adenovirus encoding endostatin encapsulated in cationic liposome in coxsackievirus and adenovirus receptor-deficient colon carcinoma murine models. Hum Gene Ther. 2011;22(9):1061-1069.

117. Lan KL, Ou-Yang F, Yen SH, Shih HL, Lan KH. Cationic liposome coupled endostatin gene for treatment of peritoneal colon cancer. Clin Exp Metastasis. 2010;27(5):307-318.

118. Sun NF, Tian AL, Hua YX, Hu SY, Hu AB. Preparation and characterization of nano-liposome-mediated FL gene in the Lovo cells. Cancer Biother Radiopharm. 2012;27(8):490-494.

119. Sun NF, Meng QY, Tian AL, et al. Nanoliposome-mediated FL/TRAIL double-gene therapy for colon cancer: in vitro and in vivo evaluation. Cancer Lett. 2012;315(1):69-77.

120. Park IK, Kim KK, Cho SH, et al. Intratumoral administration of antiKITENIN shRNA-loaded PEI-alt-PEG nanoparticles suppressed colon carcinoma established subcutaneously in mice. J Nanosci Nanotechnol. 2010;10(5):3280-3283.

121. Li S, Yu B, An P, et al. Combined liposome-mediated cytosine deaminase gene therapy with radiation in killing rectal cancer cells and xenografts in athymic mice. Clin Cancer Res. 2005;11(9):3574-3578.

122. Kline CL, Shanmugavelandy SS, Kester M, Irby RB. Delivery of PAR-4 plasmid in vivo via nanoliposomes sensitizes colon tumor cells subcutaneously implanted into nude mice to 5-FU. Cancer Biol Ther. 2009;8(19):1831-1837.

International Journal of Nanomedicine

\section{Publish your work in this journal}

The International Journal of Nanomedicine is an international, peerreviewed journal focusing on the application of nanotechnology in diagnostics, therapeutics, and drug delivery systems throughout the biomedical field. This journal is indexed on PubMed Central, MedLine, CAS, SciSearch ${ }^{\circledR}$, Current Contents ${ }^{\circledR} /$ Clinical Medicine,

\section{Dovepress}

Journal Citation Reports/Science Edition, EMBase, Scopus and the Elsevier Bibliographic databases. The manuscript management system is completely online and includes a very quick and fair peer-review system, which is all easy to use. Visit http://www.dovepress.com/ testimonials.php to read real quotes from published authors. 